\title{
Awareness of dying: it needs words
}

\author{
Martine E. Lokker • Lia van Zuylen • \\ Laetitia Veerbeek • Carin C. D. van der Rijt • \\ Agnes van der Heide
}

Received: 6 April 2011 / Accepted: 30 May 2011 / Published online: 19 June 2011

(C) The Author(s) 2011. This article is published with open access at Springerlink.com

\begin{abstract}
Purpose The purpose of this research is to study to what extent dying patients are aware of the imminence of death, whether such awareness is associated with patient characteristics, symptoms and acceptance of dying, and whether medical records and nurses' and family caregivers' views on patients' awareness of dying agree.

Methods Nurses and family caregivers of 475 deceased patients from three different care settings in the southwest Netherlands were requested to fill out questionnaires. The two groups were asked whether a patient had been aware of the imminence of death. Also, medical records were screened for statements indicating that the patient had been informed of the imminence of death.

Results Nurses completed questionnaires about 472 patients, family caregivers about 280 patients (response $59 \%$ ). According to the medical records, $51 \%$ of patients had been aware of the imminence of death; according to nurses, $58 \%$; according to family caregivers, $62 \%$. Patients who, according to their family caregiver, had been aware of the imminence of death were significantly more often in peace with dying and felt more often that life had been worth living. Inter-rater agreement on patients' awareness of dying was fair (Cohen's kappa $=0.23-0.31$ ).
\end{abstract}

M. E. Lokker $(\bowtie) \cdot$ A. van der Heide

Department of Public Health, Erasmus Medical Centre, PO Box 2040, 3000 CA Rotterdam, the Netherlands e-mail: m.lokker@erasmusmc.nl

M. E. Lokker • L. van Zuylen • C. C. D. van der Rijt Department of Medical Oncology, Erasmus Medical Centre, Rotterdam, the Netherlands

L. Veerbeek

Comprehensive Cancer Centre the Netherlands,

Leiden, the Netherlands
Conclusions Being aware of dying is associated with acceptance of dying, which supports the idea that open communication in the dying phase can contribute to the quality of the dying process. However, views on whether or not patients are aware of the imminence of death diverge between different caregivers. This suggests that communication in the dying phase of patients is open for improvement.

Keywords Awareness of dying - End of life care · Death and dying $\cdot$ Terminal care $\cdot$ Palliative care

\section{Introduction}

Being aware that death is imminent is often seen as one of the features of a good death in modern Western culture [1-4]. However, until the early 1970s, the issue of death was rarely open for discussion in health care [3,5]. Not confronting terminally ill patients openly with their upcoming death was a generally accepted code of conduct for physicians. Physicians were encouraged to give patients hope on a serious chance of recovery. The belief within the medical world was that dashing someone's hope for recovery implied heavy emotional burden and therefore could lead to an unbearable end. Nowadays, in modern Western society, this view is no longer commonly present. In accordance with currently often mentioned attributes of a good death [6], communication and openness about the situation of a patient who is approaching death are increasingly seen as preferable [3]. But even in this age, which is characterized by an emphasis on "informed consent" and "open communication", the course of a disease and its fatal conclusion are not always communicated explicitly by physicians [7]. Furthermore, there seems to be a relation between hope and the extent to which people are aware of the prognosis that they 
are going to die soon. McGrath suggests that the challenge of accepting the reality of a terminal diagnosis is so emotionally difficult that patients often oscillate between acceptance and hopeful denial [8]. It can be questioned to what extent this also holds for the dying phase, when death is expected within hours or days.

Awareness that a patient's death is imminent allows health care professionals to appropriately reset the goals of care to prevent possible harmful decisions. A prerequisite for such a reset is adequate communication. When there is shared agreement among members of the health care team that a patient is dying, the process of decision making can be better coordinated [9]. This is confirmed by a study on whether recognition of the dying phase had an impact on the number of medical interventions. That study showed that patients with a recognized dying phase received significantly less diagnostic interventions as compared to patients in whom the dying phase was not recognized [10]. Several instruments to support and promote clear communication around the dying and death of the patient have been developed, such as the Liverpool Care Pathway for the Dying Patient (LCP) [11-13]. Open awareness of the onset of the dying phase among physicians, nurses, and patients and their family caregivers is an important element of the LCP $[10,14,15]$.

In this study, we define the concept of awareness of dying as knowing that death is imminent within hours or days. This definition is in concordance with the definition of the dying phase by Ellershaw and Ward [12] which states that the dying phase means having only hours or days to live. We studied to what extent dying patients are aware of the imminence of death and whether such awareness is associated with patient characteristics, use of the LCP, symptoms and acceptance of dying (also defined as a central element of a good death [3]). In addition, we investigated the level of agreement on patients' awareness of dying between medical records, nurses and family caregivers.

\section{Patients and method}

\section{Design and population}

We performed a secondary analysis of data that were collected in the context of an intervention study that investigated the effect of using the LCP on the care and quality of life during the last 3 days of life of 475 patients [16-19]. Data collection took place between November 2003 and February 2006. Halfway this period, the LCP was introduced and subsequently used for each patient for whom the multidisciplinary team agreed that the dying phase had started.
For this study, patients were recruited from hospitals, nursing homes and home care services in the southwest of the Netherlands [19]. Patients aged 18 years or older were included when they had died during the study period in either one of these institutions. The Medical Ethical Research Committee of the Erasmus MC approved the study.

About 2 months after the death of a patient, a relative, who had been 'contact person' for the patient, received a letter from the institution that had provided terminal care. In this letter, he/she was asked for consent to be approached by the research team to fill in a written questionnaire. A reminder was sent to nonresponding relatives after 2 and 6 weeks, respectively. Only relatives who gave their consent were mailed a questionnaire. Within 1 week after the death of an eligible patient, a nurse who had been closely involved with caring for the patient during the last 3 days of life completed a questionnaire. In total, 472 nurses (response 99\%) participated. Of the relatives, 280 consented and completed a questionnaire (response 59\%).

\section{Data collection}

Within each institution, a member of the care team (mostly a nurse) collected data on age, gender, diagnosis, use of LCP and place of dying from the medical and nursing records. A question related to whether a patient had been aware of the imminence of death was included in the nurses' and family caregivers' questionnaires. Nurses were asked whether the patient had been informed about the onset of the dying phase ('yes', 'more or less', 'no'). Family caregivers were asked whether, during the last 3 days of life, it had been clear to the patient that he/she would die within a couple of days ('yes', 'more or less', 'no', 'unknown'). For the purpose of this study, 'yes' and 'more or less' were combined to represent 'yes'. In addition, medical records were screened for information indicating whether or not the patient was aware of the dying phase ('yes', 'no').

From the family caregivers' questionnaires, we also used a question concerning the consciousness of the patient $72 \mathrm{~h}$ before death, a question about whether the patient was in peace with dying and a question about the relationship of the family caregiver with the patient. Nurses were asked if they had the impression that patients during the last 3 days of their lives had felt that life had been worth living. Nurses were also asked to assess the presence of 28 symptoms during the last 3 days of life. Questions about 16 symptoms (shortness of breath, pain, fatigue, lack of appetite, need of rest, trouble sleeping, weakness, nausea, vomiting, constipation, diarrhoea, difficulty concentrating, tenseness, worrying, depressed mood and difficulty remembering) originated from the EORTC QLQ-C30 questionnaire [20]. Questions about the remaining 12 symptoms were added to the questionnaire (mouth problems/dysphagia, coughing, agitation, trouble- 
some mucus production, poor vision, restlessness, involuntary movements, itching, incontinence, pressure ulcers, confusion and anxiety) because these symptoms are common in the last phase of life [14, 21-24]. All questions concerning symptoms were scored on a four-point Likert scale. Answer options were: 'not at all', 'a little', quite a bit' or 'very much'. For the purpose of this study, these answers were recoded: 'quite a bit' and 'very much' were added up to represent 'symptom present', 'not at all' and 'a little' were added up to represent 'symptom not present'.

Analysis and statistics

Associations between awareness of dying and four patient characteristics (diagnosis, age, gender, place of dying), use of LCP, two aspects of acceptance of dying (peace with dying, life worth living) and the 28 symptoms were statistically tested using Chi-square tests. Family caregivers' rating whether a patient was aware of the imminence of death was used as reference in these analyses. Patients were excluded from these analyses when they had been unconscious during the last $72 \mathrm{~h}$ before dying. The agreement on patients' awareness of dying between medical record, nurse and family caregiver was determined for each pair (i.e. medical record-nurse, medical record-family caregiver, nurse-family caregiver) by calculating Cohen's kappas. These scores were interpreted using the Landis and Koch criteria where kappa values are associated with the following levels of agreement: $<0.00=$ poor, $0.00-0.20=$ slight, $0.21-0.40=$ fair, $0.41-0.60=$ moderate, $0.61-0.80=$ substantial and $0.81-1.00=$ almost perfect [25]. The significance level was set at $5 \%$. For the analysis of the data, we used SPSS version 17.0.

\section{Results}

Patients were on average 76 years old (range, 34-100) at the time of death (Table 1$)$. The majority (71\%) had cancer as their primary diagnosis. A small majority of the patients were female. Of all patients, $42 \%$ died in hospital, $24 \%$ in a nursing home and $29 \%$ at home. According to the medical records, $52 \%$ of all patients had been aware of the imminence of death, according to nurses, $58 \%$ and according to family caregivers, $62 \%$. The LCP, introduced halfway during the study period, was used in a third of all patients. Patients were reported to have had an average of eight different symptoms (interval, 0-20). Symptoms most prevalent during the last 3 days of life were related to lack of energy (need of rest, fatigue, weakness $74-85 \%)$, lack of appetite (73\%), difficulty concentrating (47\%) and shortness of breath (44\%).

Different variables were assessed on their association with awareness of dying. Of four patient characteristics tested, only place of dying was significantly associated with
Table 1 Characteristics of patients $(N=280)$

Characteristic

\begin{tabular}{|c|c|c|}
\hline & $N$ & (2) \\
\hline \multicolumn{3}{|l|}{ Age category } \\
\hline$\leq 75$ years & 128 & \\
\hline$>75$ years & 149 & 54 \\
\hline \multicolumn{3}{|l|}{ Gender } \\
\hline Male & 131 & 47 \\
\hline Female & 149 & 53 \\
\hline \multicolumn{3}{|l|}{ Diagnosis } \\
\hline Cancer & 189 & 71 \\
\hline Non-cancer & 78 & 29 \\
\hline \multicolumn{3}{|l|}{ Place of dying } \\
\hline At home & 82 & 29 \\
\hline Nursing home & 67 & 24 \\
\hline Hospital & 117 & 42 \\
\hline Elsewhere & 14 & \\
\hline \multicolumn{3}{|l|}{ Awareness of dying } \\
\hline According to the medical record patient was aware & 145 & 52 \\
\hline According to nurse patient was aware & 163 & 58 \\
\hline According to family caregiver patient was aware & 173 & 62 \\
\hline \multicolumn{3}{|l|}{ Relationship with family caregiver/proxy } \\
\hline Partner & 106 & 38 \\
\hline Parent/child & 122 & 44 \\
\hline Sibling & 12 & \\
\hline Other family & 28 & 10 \\
\hline Other non-family & 11 & \\
\hline \multicolumn{3}{|l|}{ Use of LCP } \\
\hline No & 179 & 64 \\
\hline Yes & 101 & 36 \\
\hline Symptom prevalence during the last 3 days of life & $\mathrm{N}^{1} / \mathrm{N}^{2}$ & $\%$ \\
\hline In need of rest & $224 / 265$ & 85 \\
\hline Fatigue & $215 / 264$ & 81 \\
\hline Weakness & $195 / 263$ & 74 \\
\hline Lack of appetite & $191 / 263$ & 73 \\
\hline Difficulty concentrating & $118 / 251$ & 47 \\
\hline Shortness of breath & $116 / 266$ & 44 \\
\hline Incontinence & $110 / 266$ & 41 \\
\hline Pain & $106 / 271$ & 39 \\
\hline Mouth problems/dysphagia & $77 / 207$ & 37 \\
\hline Restlessness & $100 / 269$ & 37 \\
\hline Worrying & $86 / 250$ & 34 \\
\hline Difficulty remembering & $83 / 253$ & 33 \\
\hline Tenseness & $68 / 252$ & 27 \\
\hline Troublesome mucus & $73 / 271$ & 27 \\
\hline Confusion & $68 / 263$ & 26 \\
\hline Anxiety & $67 / 260$ & 26 \\
\hline Trouble sleeping & $64 / 266$ & 24 \\
\hline Depressed mood & $58 / 247$ & 23 \\
\hline Poor vision & $45 / 252$ & 18 \\
\hline Coughing & $37 / 214$ & 17 \\
\hline
\end{tabular}


Table 1 (continued)

\begin{tabular}{lrr}
\hline Characteristic & & \\
\hline Involuntary movements & $43 / 268$ & 16 \\
Nausea & $41 / 266$ & 15 \\
Constipation & $38 / 261$ & 15 \\
Pressure ulcers & $36 / 270$ & 13 \\
Vomiting & $29 / 267$ & 11 \\
Agitation & $25 / 256$ & 10 \\
Diarrhoea & $23 / 261$ & 9 \\
Itching & $12 / 265$ & 5 \\
\hline
\end{tabular}

$N^{I}$ number of patients in whom the symptom was present, $N^{2}$ number of patients for whom the nurse answered the item

awareness of dying ( $p=0.012$; Table 2$)$. Of patients dying at home, $83 \%$ were aware of the imminence of death compared to $68 \%$ of patients dying in a hospital and $62 \%$ of patients dying in a nursing home.

Patients who were aware of the imminence of death were more often in peace with dying $(p=0.000)$ and felt more often that life had been worth living $(p=0.009)$ compared to patients who were not aware (Table 3). No clear association between symptoms and awareness was found, except for two symptoms. Patients aware of dying more often experienced a lack of appetite $(p=0.049)$ and less often experienced tenseness $(p=0.014)$ compared to patients not aware of dying (not in Table).

The percentage of patients that, according to the family caregivers, had been aware of the imminence of death was stable before and after introduction of the LCP $(63 \%$ before, $62 \%$ after, $p=0.474)$. For nurses, the percentage of patients that they thought had been aware of the imminence of death was $54 \%$ before and $62 \%$ after introduction $(p=0.143)$. The percentage of patients for whom a statement was found in the medical record indicating that he or she was aware of the dying phase was $38 \%$ before and $64 \%$ after the introduction of the LCP ( $p=0.000$; not in Table). The level of agreement, as assessed by Cohen's kappa, on whether or not the patient had been aware of the imminence of death was 0.23 for the medical records and family caregivers, 0.28 for nurses and caregivers and 0.31 for the medical records and nurses (Table 4). The inter-rater agreement was not related to patient characteristics, such as age, gender, diagnosis, use of the LCP or place of death (not in Table).

\section{Discussion/conclusion}

According to the medical records, nurses and caregivers, $51-62 \%$ of patients had been aware of the imminence of death in the last days of life. Patients dying at home were more often aware of the imminence of death compared to patients who died in a hospital or in a nursing home. Whether a patient was aware of dying was not clearly associated with symptoms. Finally, awareness turned out to be associated with acceptance of dying; patients who were aware of the imminence of death were more often in peace with dying and felt more often that life had been worth living than patients who were not aware.

In 1965, Glaser and Strauss described four categories of 'awareness of dying', used for deaths expected within hours, days, weeks or months of a patient's life. These categories ranged from closed awareness (the patient does not recognize his impending death even though everyone else does) through suspicion awareness (the patient suspects what the others know and therefore attempts to confirm or invalidate his suspicion) and mutual pretence (each party defines the patient as dying, but each pretends that the other has not done so) to open awareness (caregivers and patient both are aware that the patient is dying, and act on this awareness relatively openly) [26]. In 1997, Seale et al. [27] argued that 'a preference for open awareness of dying is now well established in terminal care settings and amongst the general population in the UK, USA and other Anglophone countries'. It is plausible that this is also true for the Netherlands. However, the percentage of cases in our study in which dying patients were openly aware of the imminence of death within days was only $51-62 \%$, depending on whether it was assessed through the medical record, the nurse or a family member.

Table 2 Patients' characteristics and awareness of the imminence of death $(n=213$; excluding unconscious patients $(n=67))$

\begin{tabular}{lccc}
\hline & \multicolumn{2}{l}{$\begin{array}{l}\text { Patient aware of } \\
\text { the imminence of death }{ }^{\mathrm{a}}\end{array}$} & \\
\cline { 2 - 3 } & Yes & Nolue \\
& & & \\
\hline Diagnosis & & \\
Cancer $(n=134)$ & $72 \%$ & $28 \%$ & 0.477 \\
Non-cancer $(n=43)$ & $70 \%$ & $30 \%$ & \\
Age & & & \\
$\leq 75$ years $(n=82)$ & $72 \%$ & $28 \%$ & 0.560 \\
$>75$ years $(n=103)$ & $72 \%$ & $28 \%$ & \\
Gender & & & \\
Male $(n=87)$ & $69 \%$ & $31 \%$ & \\
Female $(n=100)$ & $73 \%$ & $27 \%$ & 0.328 \\
Place of dying & & & \\
At home $(n=53)$ & $83 \%$ & $17 \%$ & \\
Nursing home $(n=87)$ & $62 \%$ & $38 \%$ & \\
Hospital $(n=38)$ & $68 \%$ & $32 \%$ & \\
Elsewhere $(n=9)$ & $100 \%$ & $0 \%$ & \\
\hline a Excluding patients for & whom awareness & was unknown $(N=25) /$ \\
missing $(n=1)$ & & & \\
${ }^{\mathrm{b}}$ Chi-square test & & &
\end{tabular}


Table 3 Awareness of the imminence of death and acceptance of dying $(n=213$; excluding unconscious patients $(n=67))$

\begin{tabular}{|c|c|c|c|c|c|c|}
\hline & & \multicolumn{4}{|c|}{ Patient aware of the imminence of death ${ }^{\mathrm{a}}$} & \multirow[t]{3}{*}{$P$ value ${ }^{\mathrm{b}}$} \\
\hline & & \multicolumn{2}{|l|}{ Yes } & \multicolumn{2}{|l|}{ No } & \\
\hline & & $N$ & $\%$ & $N$ & $\%$ & \\
\hline & & 118 & & 36 & & \\
\hline \multirow[t]{3}{*}{ Patient in peace with dying } & Yes & & 85 & & 56 & 0.000 \\
\hline & No & & 15 & & 44 & \\
\hline & & 120 & & 44 & & \\
\hline \multirow[t]{2}{*}{ During the last 3 days, patient felt that life had been worth living } & Yes & & 72 & & 50 & 0.009 \\
\hline & No & & 28 & & 50 & \\
\hline
\end{tabular}

${ }^{\text {a }}$ Excluding patients for whom awareness was unknown $(N=25) / \operatorname{missing}(n=1)$

${ }^{\mathrm{b}}$ Chi-square test

Studies on awareness of dying and its determinants are scarce $[2,7,27]$. The fact that over one third of patients was not considered being aware of the imminence of death probably reflects, at least partly, the difficulty of diagnosing dying, even in settings where death is a relatively common event. The natural course of a lethal disease is typically not a straightforward matter of steady or stepwise decline from diagnosis to death. Consequently, it can be difficult to distinguish a decline in the patient's condition due to an acute reversible problem from a decline due to the progression of a life-limiting illness towards death [9]. This seems to be even more complex for nonmalignant diseases because these often have 'entry-reentry' death trajectories, involving episodic, acute exacerbations, frequent hospitalisation, stabilisation and subsequent further decline, making determination of the end of life phase more problematic $[28,29]$. Our analyses however did not reveal a relation between awareness of dying and malignant or nonmalignant diseases. Previous research has also shown that prognostication at the end of life is difficult, although predictions become more accurate when patients are closer to death, a finding which has been referred to as the 'horizon effect' [30-32]. The finding that age and gender were not associated with awareness of dying is in agreement with a study by Seale et al. [27]. In Seale's study, awareness of dying was more common among younger family caregivers and among patients who died from noncancer diseases. Comparisons were however limited to patients in 'full open awareness' (where there is not only knowledge of dying but also a value commitment towards openness) and patients in 'closed awareness', leaving all possible other types of awareness and a large proportion of patients in more limited types of open awareness, out of the

Table 4 Patients' awareness of the imminence of death: inter-rater agreement between medical records, nurses and family caregivers $(n=250$; excluding patients for where not all three sources answered this question $(n=30))$

\begin{tabular}{|c|c|c|c|c|c|c|c|c|c|c|}
\hline Rating of awareness & \multicolumn{3}{|c|}{ Medical record } & \multicolumn{3}{|c|}{ Nurse } & \multicolumn{4}{|c|}{ Caregiver } \\
\hline $\begin{array}{l}\text { Was the patient aware } \\
\text { that he was going to die? }\end{array}$ & Yes & No & Missing & Yes & No & Missing & Yes & No & Missing & Unknown \\
\hline & $51 \%$ & $21 \%$ & $28 \%$ & $58 \%$ & $33 \%$ & $9 \%$ & $62 \%$ & $25 \%$ & $1 \%$ & $12 \%$ \\
\hline
\end{tabular}

Inter-rater agreement

Medical record and Nurse

Medical record and

Caregiver

Nurse and Caregiver

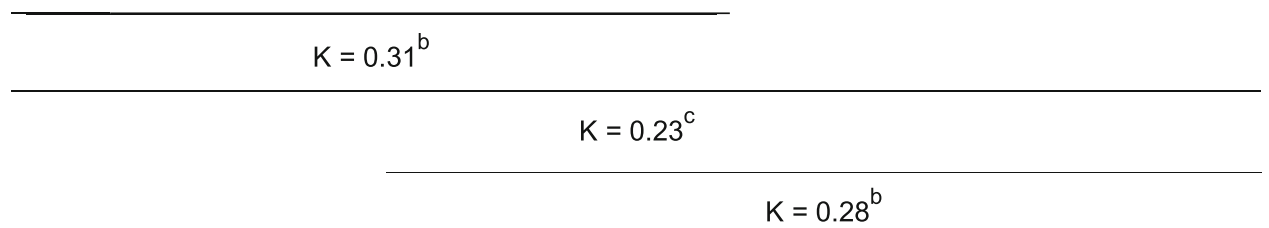

Interpretation of Cohen's kappa - poor agreement $\leq 0.00$, slight agreement $0.00-0.20$, fair agreement $0.21-0.40$, moderate agreement $0.41-0.60$, substantial agreement $0.61-0.80$, almost perfect agreement $0.81-1.0$ [25]

$* p=0.000 ; * * p=0.003$ 
analyses. This could perhaps explain why in our study we did not find this same association. Our finding that patients dying at home were more often aware of the imminence of death than patients dying in a hospital or nursing home is probably related to the selection of patients who die in these settings. Severely ill patients in the Netherlands are often admitted to the hospital with the aim of addressing complications or relieving complex symptoms, in the expectation that they will be discharged to go home. Additionally, in the nursing home, a higher percentage of patients with dementia probably resulted in a lower percentage of patients being aware of dying. Our finding is consistent with a previous research by Seale et al. [27] who also found higher frequencies of awareness of dying among patients dying at home. They hypothesise that patients who are aware of their imminent death have a greater tendency to control the circumstances of death, including their place of death. Patients who were aware of the imminence of death were, compared to patients who were not aware, significantly more often in peace with dying and felt more often that life had been worth living. Whether awareness of dying leads to acceptance of dying or acceptance leads to awareness remains unclear.

The medical record and nurses' and family caregivers' perspectives on whether or not patients had been aware of the imminence of death differed in a substantial number of cases. Deviating perspectives on awareness of dying were also found by Rich et al. [33] in a study concerning the experiences of medical staff and family of deceased patients. These authors also found only fair agreement between medical staff and family on the question 'did you know that death was imminent?' Apparently, communication between physician, nurses and family in the dying phase is not optimal in a substantial number of cases. The percentage of cases in which, according to the medical record, the patient had been aware increased significantly after the introduction of the LCP. However, the agreement between the three groups did not increase accordingly. Although use of the LCP seems to improve the knowledge of physicians and nurses about patients' awareness of dying, the alignment between all parties involved is not optimal. The use of the LCP in this study was limited to a particular period, and physicians and nurses were new in using this instrument. More extended use of the instrument may lead to more communication and mutual knowledge about patients in the dying phase.

Our study had some limitations. Firstly, all data were collected after the death of a patient. It was therefore not possible to obtain information from the patient. In addition, family caregivers and nurses provided information retrospectively, and a certain degree of recall bias can therefore not be precluded. Secondly, the cross-sectional design of the study makes inferences about causality not possible. Finally, our study population is not completely representative for the Dutch population. In our study, the mean age of death was lower (76) than in the Dutch population (80) [34], and the proportion of cancer patients $(71 \%)$ was higher than the proportion of cancer deaths in the Dutch population (30\%) [35]. Moreover, the place of dying of the patients in this study was not fully comparable with the distribution in the Netherlands. In our study, the distribution was $29 \%$ of patients dying at home, $24 \%$ in a nursing home and $42 \%$ in a hospital, compared to the distribution in the Dutch population which is $38 \%, 23 \%$ and $33 \%$ [36].

In conclusion, our finding that being aware of the imminence of death is associated with acceptance of dying supports the idea that open communication in the dying phase between physicians, nurses, patients and family caregivers can contribute to the quality of the dying process. Communication about all potentially relevant aspects of the situation of a patient in the dying phase is a requirement for adequate patient-centred care and also an important focus of the LCP. Findings of the current study suggest that the communication in the dying phase of patients is not yet optimal and open for improvement. The most suitable time and strategy to enhance open communication about the dying phase cannot be concluded from our data and should be a topic in future research.

Acknowledgements This work was supported by Erasmus MC, Rotterdam, The Netherlands (internal grant).

Conflicts of interest statement The author(s) declare(s) that there is no conflict of interest.

Open Access This article is distributed under the terms of the Creative Commons Attribution Noncommercial License which permits any noncommercial use, distribution, and reproduction in any medium, provided the original author(s) and source are credited.

\section{References}

1. Clark D (2002) Between hope and acceptance: the medicalisation of dying. BMJ 324(7342):905-907

2. Field D, Copp G (1999) Communication and awareness about dying in the 1990s. Palliat Med 13(6):459-468

3. Goldsteen M et al (2006) What is a good death? Terminally ill patients dealing with normative expectations around death and dying. Patient Educ Couns 64(1-3):378-386

4. Smith R (2000) A good death. An important aim for health services and for us all. BMJ 320(7228):129-130

5. Steinhauser KE et al (2001) Preparing for the end of life: preferences of patients, families, physicians, and other care providers. J Pain Symptom Manage 22(3):727-737

6. Rietjens JA et al (2006) Preferences of the Dutch general public for a good death and associations with attitudes towards end-oflife decision-making. Palliat Med 20(7):685-692

7. Francke AL, Willems DL (2005) Terminal patients' awareness of impending death: the impact upon requesting adequate care. Cancer Nurs 28(3):241-247 
8. McGrath P (2002) End-of-life care for hematological malignancies: the 'technological imperative' and palliative care. J Palliat Care 18(1):39-47

9. Stevenson J, Ellershaw J (2008) Prognostication in the imminently dying patient. In: Glare P, Christakis NA (eds) Prognosis in advanced cancer. Oxford University Press, New York

10. Veerbeek L et al (2008) Does recognition of the dying phase have an effect on the use of medical interventions? J Palliat Care 24(2):94-99

11. Ellershaw J (2003) Introduction. In: Ellershaw J, Wilkinson S (eds) Care of the dying. Oxford University Press, New York

12. Ellershaw J, Ward C (2003) Care of the dying patient: the last hours or days of life. BMJ 326(7379):30-34

13. Ellershaw JE et al (1997) Developing an integrated care pathway for the dying patient. Eur J Palliat Care 4:203-207

14. Ellershaw $J$ et al (2001) Care of the dying: setting standards for symptom control in the last 48 hours of life. J Pain Symptom Manage 21(1):12-17

15. Kinder C, Ellershaw J (2003) How to use the Liverpool Care pathway for the dying patient? In: Ellershaw J, Wilkinson S (eds) Care of the dying. Oxford University Press, New York

16. van der Heide A et al (2010) End-of-life decision making for cancer patients in different clinical settings and the impact of the LCP. J Pain Symptom Manage 39(1):33-43

17. Veerbeek L et al (2008) Using the LCP: bereaved relatives' assessments of communication and bereavement. Am J Hosp Palliat Care 25(3):207-214

18. Veerbeek L et al (2006) Audit of the Liverpool Care Pathway for the dying patient in a Dutch cancer hospital. J Palliat Care 22(4):305-308

19. Veerbeek L et al (2008) The effect of the Liverpool Care Pathway for the dying: a multi-centre study. Palliat Med 22 (2): $145-151$

20. Sneeuw KC et al (1998) Comparison of patient and proxy EORTC QLQ-C30 ratings in assessing the quality of life of cancer patients. J Clin Epidemiol 51(7):617-631

21. Chochinov HM et al (2002) Dignity in the terminally ill: a crosssectional, cohort study. Lancet 360(9350):2026-2030
22. Coyle $\mathrm{N}$ et al (1990) Character of terminal illness in the advanced cancer patient: pain and other symptoms during the last four weeks of life. J Pain Symptom Manage 5(2):83-93

23. Klinkenberg $M$ et al (2004) Symptom burden in the last week of life. J Pain Symptom Manage 27(1):5-13

24. Lichter I, Hunt E (1990) The last 48 hours of life. J Palliat Care 6 (4): $7-15$

25. Landis JR, Koch GG (1977) The measurement of observer agreement for categorical data. Biometrics 33(1):159-174

26. Glaser BG, Strauss AL (1965) Awareness of dying. Aldine, Chicago

27. Seale C, Addington-Hall J, McCarthy M (1997) Awareness of dying: prevalence, causes and consequences. Soc Sci Med 45 (3):477-484

28. Coventry PA et al (2005) Prediction of appropriate timing of palliative care for older adults with non-malignant life-threatening disease: a systematic review. Age Ageing 34(3):218-227

29. Murtagh FE, Preston M, Higginson I (2004) Patterns of dying: palliative care for non-malignant disease. Clin Med 4(1):3944

30. Gibbins $\mathrm{J}$ et al (2009) Diagnosing dying in the acute hospital setting - are we too late? Clin Med 9(2):116-119

31. Glare P et al (2003) A systematic review of physicians' survival predictions in terminally ill cancer patients. BMJ 327(7408):195198

32. Higginson IJ, Costantini M (2002) Accuracy of prognosis estimates by four palliative care teams: a prospective cohort study. BMC Palliat Care 1(1):1

33. Rich SE, Williams CS, Zimmerman S (2009) Concordance of family and staff member reports about end of life in assisted living and nursing homes. Gerontologist 50(1):112-120

34. World Health Organization (2010) Available from: http:// www.who.int/whosis/whostat/EN WHS10 Full.pdf. Accessed 16 Oct 2010

35. Statistics Netherlands. Gezondheid en zorg in cijfers. 2009

36. Statistics Netherlands. Central Death Registry. 2007 